\title{
Analysis of Potential of Inbound Tourism for Major Sources of Tourists and Influencing Factors in China
}

\author{
Wenrong Pan*, Ying Liu, Jiang Tong \\ School of Statistics, Jiangxi University of Finance and Economics, Nanchang, China \\ Email address: \\ 820966059@qq.com (Wenrong Pan),1123538947@qq.com (Ying Liu),2661520861@qq.com (Jiang Tong) \\ ${ }^{*}$ Corresponding author
}

To cite this article:

Wenrong Pan, Ying Liu, Jiang Tong. Analysis of Potential of Inbound Tourism for Major Sources of Tourists and Influencing Factors in China. American Journal of Applied Mathematics. Vol. 6, No. 3, 2018, pp. 128-134. doi: 10.11648/j.ajam.20180603.14

Received: July 21, 2018; Accepted: August 1, 2018; Published: August 29, 2018

\begin{abstract}
Since 2015, the inbound visitors of most sources of tourists such as Japan, Russia and Malaysia in China have been on a growing decrease. While the inbound visitors of some sources of tourists such as the United States, Germany and Thailand have only shown some subtle changes. Therefore, China's inbound tourism is facing an increasingly great downward pressure. On the basis of existing researches, this paper screens indicators in light of the economic development of the source of tourists, the appeal of Chinese culture, the economic and trade exchanges with China and transportation costs in China. In consideration of cultural appeal, this paper establishes a new indicator system to evaluate the potential of inbound tourism of major sources of tourists. It finds out the problems in the process of their development and figures out some solutions in order to improve the competitiveness of China's tourism. At the same time, this paper utilizes the principal component analysis to evaluate the potential of inbound tourism for nineteen sources of tourists with the help of cross-section data in 2015. It also ranks in a comprehensive way the major influencing factors of their potential of inbound tourism with direct oblimin. The ranking in order of importance is the rate of outbound tourism, the per capita national income, the proportion of the 25-64 age group, the number of Confucius Institutes, the number of overseas students in China, as well as investment in China. The evaluation result shows that South Korea, the United States and India are the sources of tourists with the highest potential in China. These countries such as Singapore, Germany, Russia, the United Kingdom, Australia, Canada, and France have certain potential to be the sources of tourists. Moreover, Philippines, Indonesia, and Mongolia are at the end of the ranking.
\end{abstract}

Keywords: Inbound Tourism, Cultural Appeal, Principal Component Analysis, Direct Oblimin

\section{Introduction}

As one of the countries with richest tourism resources in the world, China is pretty attractive to tourists from all over the world. Since the reform and opening up, China's inbound tourism has achieved remarkable achievements. By 2015, the foreign exchange income from tourism has reached 113.65 billion dollars, which was 432.13 times than that in 1978 . However, in 2015, the number of inbound tourists was 25.9854 million, down from 26.1097 million in 2007. The downward pressure on inbound tourism continued to increase. China is in an urgent need to make great strides in its inbound tourism $[1,8,10]$. Thus, accurate location and analysis of the sources of tourists play a positive and significant role in tourism competitiveness, revenue and development.
Most of scholars at home and abroad started their researches on the factors of influencing the inbound tourism from the prospective of the economic development of the source of tourists, economic and trade exchanges with China, and transportation costs in China. They usually chose indicators such as the per capita national income, the level of urbanization, trade and investment and transportation costs to conduct their researches [2-7]. However, China has a profound culture. Against the background of booming international tourism, the identity and belonging towards the Chinese culture are served as reasons for foreigners to travel to China. There is no doubt that culture exerts a significant influence on the development of China's inbound tourism. It advances the development of traditional Chinese culture on 
the one side, and builds a platform for the world to know about China on the other side [9, 12, 15]. For instance, China has set Confucius Institutes over the globe. Under the appeal of Chinese culture, the number of foreign students is on a great increase. From the perspective of the source of tourists, this paper embraces cultural appeal into the indicator system, evaluates the potential of inbound tourism for major sources of tourists with principal component analysis, and finds out the factors that influence the evaluation of inbound tourism with direct oblimin. At the beginning of the paper, it analyses the current situation of inbound tourism in China to introduce the theme. It gives a detailed explanation over the indicator system and the source of the data. At the same time, it evaluates the potential of the sources of tourists and finds out the factors which influence the evaluation results in China. At the last part of this paper, it arrives at some conclusions. There are two innovative points in this paper. One is that it embraces the cultural appeal into the indicator system. The other is that it finds out the major factors of influencing the potential of inbound tourism for these countries with direct oblimin.

\section{The Construction of Indicator System and Data Sources}

Based on the former researches, this paper builds a new indicator system to evaluate the potential of nineteen countries of tourists, including South Korea, USA, India, Singapore, Germany, Russia, UK, Australia, Canada, France, Japan, Netherlands, Thailand, New Zealand, Malaysia, Italy, Indonesia, Mongolia and Philippines. In Table 1 , the primary indicators are set on the basis of the economic development of the source of tourists, cultural appeal, economic and trade exchanges with China, and transportation costs in China.

The reasons for setting the secondary indicators are as follows: in terms of the economic development of the source of tourists, the rate of outbound tourism can reflect the comprehensive level of a nation traveling abroad. The 25-64 age group is regarded as the best age of traveling abroad in that the average rate of tourists concerning inbound tourism at this age accounts for seventy percent. With respects to cultural appeal, the number of Confucius Institutes in other countries reveals China's cultural communication to these countries and the influence of Chinese culture on these countries to a great extent. At the same time, the number of foreign students in China reflects their identity towards Chinese culture. The number of Confucius Institutes and foreign students has a representativeness and objectivity over the research on Chinese cultural appeal in other countries. Concerning economic and trade exchanges with China and transportation costs in China, the total volume of the trade shows how open a country is towards China. The transportation costs have a great account on the total expense of tourism.

The data in this paper mainly comes from the International Statistical Yearbook 2015, China Statistical Yearbook 2016 and relevant news reports. In addition, the data of transportation costs such as aviation, ships, railways, and highways are derived from the selling prices on major websites in the current year. In the calculation of transportation costs, most tourists choose to travel by airplane to China. However, there are distance differences between different countries. Calculating the transportation costs to China, this paper puts enough focus on the round-trip air tickets price from each country to China. In order to ensure the reliability and validity of the data, the price of air tickets in different years is adjusted in conjunction with the Consumer Price Index (CPI). Due to the quarterly difference in ticket prices, the weighted value of each quarter is set on the basis of the number of visitors from each country in China and the ticket price is aggregated in order to obtain the final transportation costs. Since the raw data of the per capita national income, investment in China and total trade volume are calculated in US dollars, the data are all exchanged into RMB according to the average exchange rate of 6.2284 in 2015 to unify the units. Thus, the indicator system to evaluate the potential of the country of tourists is built in Table 1. In consideration of the different variable units, all variables are standardized before data processing.

Table 1. Evaluation indicator system and symbols.

\begin{tabular}{|c|c|c|}
\hline Primary indicators & Secondary indicators & Symbols \\
\hline \multirow{6}{*}{ The economic development of the source of tourists } & The per capita national income (Yuan/person) & $\mathrm{X} 1$ \\
\hline & The level of urbanization $(\%)$ & $\mathrm{X} 2$ \\
\hline & Household consumption rate $(\%)$ & $\mathrm{X} 4$ \\
\hline & Average years of schooling (year/person) & $\mathrm{X} 5$ \\
\hline & The proportion of the $25-64$ age group (\%) & $\mathrm{X} 6$ \\
\hline & Unemployment rate $(\%)$ & $\mathrm{X} 7$ \\
\hline \multirow{2}{*}{ Cultural appeal } & Number of Confucius Institutes & $\mathrm{X} 8$ \\
\hline & Number of overseas students in China (person) & X9 \\
\hline \multirow{3}{*}{ Economic and trade exchanges with China and transportation costs in China } & Investment in China (Yuan) & $\mathrm{X} 10$ \\
\hline & Total trade with China (Yuan) & $\mathrm{X} 11$ \\
\hline & Transportation costs (Yuan) & $\mathrm{X} 12$ \\
\hline
\end{tabular}




\section{Evaluating the Potential of Inbound Tourism for Major Sources of Tourist and Analysing Influencing Factors}

\subsection{Principal Component Analysis of the Evaluation}

\subsubsection{Empirical Analysis Process}

According to the indicator system, this paper uses
SPSS19.0 for analysis. The test result tells that the value of $\mathrm{P}$ in the Bartlett's test of sphericity is close to 0. It supposes that the significance level $a$ is 0.05 . In this sense, the null hypothesis should be rejected. At the same time, the value of Kaiser-Meyer-Olkin (KMO) is 0.665. It's reasonable to arrive at the conclusion that the original variables are suitable for principal component analysis according to the KMO.

Table 2. Principal component extraction and variance contribution rate.

\begin{tabular}{llll}
\hline Principal component & Characteristic value & Variance contribution rate (\%) & Accumulated variance contribution rate (\%) \\
\hline F1 & 4.116 & 34.296 & 34.296 \\
F2 & 3.208 & 26.733 & 61.030 \\
F3 & 17.559 & 78.589 \\
F4 & 2.107 & 5.430 & 84.019 \\
\hline
\end{tabular}

Table 2 shows that the accumulated variance contribution rate of the first four principal components has reached $84.019 \%$, which indicates that these components contain most of the information of the twelve original evaluation indicators and they are irrelevant to each other. In the meantime, it avoids the information overlaps between indicators, therefore, the four components can be used to evaluate the potential of inbound tourism for the nineteen sources of tourists.

Table 3. Compound matrix of principal component indicators.

\begin{tabular}{llll}
\hline Evaluation indicators & F1 & F2 & F3 \\
\hline The per capita national income (X1) & 0.933 & 0.120 & -0.096 \\
The level of urbanization (X2) & 0.810 & 0.417 & -0.188 \\
The rate of outbound tourism (X3) & 0.408 & 0.790 & -0.607 \\
Household consumption rate (X4) & -0.032 & -0.843 & 0.053 \\
Average number of years of schooling (X5) & 0.893 & 0.054 & 0.145 \\
The proportion of the 25-64 age group (X6) & -0.203 & 0.825 & 0.071 \\
Unemployment rate (X7) & 0.335 & -0.638 & -0.294 \\
Number of Confucius Institutes (X8) & 0.514 & -0.124 & 0.752 \\
Number of overseas students in China (X9) & -0.185 & 0.416 & 0.382 \\
Investment in China (X10) & 0.330 & -0.453 & 0.223 \\
Total Trade with China (X11) & 0.646 & -0.090 & 0.255 \\
Transportation costs (X12) & 0.804 & -0.484 & 0.147 \\
\hline
\end{tabular}

Table 3 shows that in the principal component F1, indicators such as the per capita national income, the average years of schooling, the level of urbanization, and the transportation costs account for a large proportion, which means F1 puts its focus on the economic development of the source of tourists and the transportation costs in China. As to the principal component $\mathrm{F} 2$, the household consumption rate, the proportion of the 25-64 age group, and the rate of outbound tourism account for a large proportion. It can be inferred that F2 mainly represents the willingness of tourists coming from these countries. Concerning the principal component F3, the number of Confucius Institute, the number of overseas students in China is relatively large. It means that F3 mainly represents the influence and appeal of Chinese culture on these countries. With regards to the principal component F4, only the investment in China accounts for a large proportion, which represents the trade level between the source of tourists and China. Four calculation expressions can be obtained according to the linear combination formula of the extracted principal components.

$$
F_{i}=\frac{a_{i 1}}{\sqrt{\lambda_{i}}} X_{1}^{*}+\frac{a_{i 2}}{\sqrt{\lambda_{i}}} X_{2}^{*}+\cdots \frac{a_{i k}}{\sqrt{\lambda_{i}}} X_{k}^{*},(i=1,2, \cdots, m)
$$

First principal component

$$
\begin{aligned}
& F_{1}=0.46 X_{1}^{*}+0.399 X_{2}^{*}+0.201 X_{3}^{*}-0.016 X_{4}^{*}+0.44 X_{5}^{*}-0.1001 X_{6}^{*}+0.165 X_{7}^{*}+0.253 X_{8}^{*} \\
& -0.091 X_{9}^{*}+0.163 X_{10}^{*}+0.318 X_{11}^{*}+0.396 X_{12}^{*}
\end{aligned}
$$

Second principal component 


$$
\begin{aligned}
& F_{2}=0.067 X_{1}^{*}+0.233 X_{2}^{*}+0.274 X_{3}^{*}-0.471 X_{4}^{*}+0.03 X_{5}^{*}+0.461 X_{6}^{*}-0.356 X_{7}^{*}-0.069 X_{8}^{*} \\
& +0.232 X_{9}^{*}+0.414 X_{10}^{*}-0.05 X_{11}^{*}-0.27 X_{12}^{*}
\end{aligned}
$$

Third principal component

$$
\begin{aligned}
& F_{3}=-0.066 X_{1}^{*}-0.130 X_{2}^{*}-0.418 X_{3}^{*}+0.198 X_{4}^{*}+0.049 X_{5}^{*}+0.076 X_{6}^{*}-0.203 X_{7}^{*}+0.518 X_{8}^{*} \\
& +0.548 X_{9}^{*}+0.104 X_{10}^{*}+0.363 X_{11}^{*}-0.063 X_{12}^{*}
\end{aligned}
$$

Fourth principal component

$$
\begin{aligned}
& F_{4}=-0.134 X_{1}^{*}+0.066 X_{2}^{*}+0.180 X_{3}^{*}-0.025 X_{4}^{*}+0.298 X_{5}^{*}+0.473 X_{6}^{*}+0.276 X_{7}^{*}+0.316 X_{8}^{*} \\
& +0.182 X_{9}^{*}-0.561 X_{10}^{*}-0.328 X_{11}^{*}+0.005 X_{12}^{*}
\end{aligned}
$$

\begin{tabular}{|c|c|c|c|c|c|c|}
\hline Countries & F1 & F2 & F3 & F4 & $\mathbf{F}$ & Comprehensive ranking \\
\hline Korea & -0.420 & 3.292 & 3.249 & 0.830 & 6.950 & 1 \\
\hline USA & 3.128 & -1.200 & 3.019 & -0.653 & 4.294 & 2 \\
\hline India & 3.679 & 1.074 & 0.414 & -1.099 & 4.068 & 3 \\
\hline Singapore & 1.037 & 5.015 & -1.887 & -1.223 & 2.943 & 4 \\
\hline Germany & 2.085 & 0.154 & 0.445 & -0.220 & 2.464 & 5 \\
\hline Russia & -0.605 & 0.597 & 0.608 & 1.318 & 1.919 & 6 \\
\hline Britain & 2.084 & -1.380 & 0.378 & 0.766 & 1.847 & 7 \\
\hline Australia & 1.451 & -0.363 & -0.502 & 0.398 & 0.984 & 8 \\
\hline Canada & 1.648 & -0.401 & -1.004 & 0.734 & 0.977 & 9 \\
\hline France & 1.359 & -1.196 & -0.028 & -0.098 & 0.037 & 10 \\
\hline Japan & 1.003 & -0.067 & 0.778 & -1.776 & -0.062 & 11 \\
\hline Netherlands & 1.608 & 0.383 & -2.063 & -0.018 & -0.090 & 12 \\
\hline Thailand & -3.241 & 1.194 & 1.361 & 0.434 & -0.252 & 13 \\
\hline New Zealand & 0.573 & -0.642 & -1.369 & 0.249 & -1.190 & 14 \\
\hline Malaysia & -1.521 & 1.085 & -1.137 & 0.125 & -1.448 & 15 \\
\hline Italy & 0.532 & -2.139 & -0.801 & 0.348 & -2.060 & 16 \\
\hline Mongolia & -1.973 & 0.093 & -1.413 & 0.838 & -2.455 & 17 \\
\hline Indonesia & -2.594 & -0.719 & 0.074 & -0.225 & -3.464 & 18 \\
\hline The Philippines & -2.477 & -2.630 & -0.122 & -0.728 & -5.957 & 19 \\
\hline
\end{tabular}

Substituting the standardized data into equations (2)-(5), the scores of the four principal components of nineteen countries are obtained. The weighted average is calculated based on the contribution rate of principal components, as shown in Table 4.

$$
\mathrm{F}=\frac{34.296 \%}{84.019 \%} \mathrm{~F}_{1}+\frac{26.733 \%}{84.019 \%} \mathrm{~F}_{2}+\frac{17.559 \%}{84.019 \%} \mathrm{~F}_{3}+\frac{5.430 \%}{84.019 \%} \mathrm{~F}_{4}
$$

Table 4. Evaluation results of potential of nineteen countries of tourists.

\subsubsection{Countries with the Highest Potential of Inbound Tourism}

Table 4 shows that South Korea is ranked first. South Korea is adjacent to China and the transportation in terms of water, land and air is extremely convenient. Most of the cities in China have direct flights to South Korea, which greatly facilitates the travel of South Korean tourists. Since ancient times, Chinese culture, such as characters, political system and agricultural technology, Taoism, and Chinese Buddhism has had a profound influence on South Korea in its language, ideology, social structure and the development of productivity. Moreover, Chinese culture has a great appeal to South Korean tourists in cultural identity. Since the 1960s, the South Korean government has implemented an "exportoriented" economic strategy. Within a few decades, it has become a medium-developed country. Its national living standards and the trade volume with China have been improved and increased in a significant fashion. Thus, South Korea will have great potential as a source of tourists in the future.

The United States is ranked second in the evaluation result. As the only superpower in the world, the United States has strong economic strength. The people in this country normally choose to have an overseas trip after getting certain wealth. Since the establishment of diplomatic relations between China and the United States, both countries have deepened their economic exchanges and China has become the largest trading partner of the United States. As the largest developing country and the largest developed country respectively, China and the United States maintain close ties in cultural exchanges, economy and politics. As a nation of immigrants, the United States has always been a multicultural country. Chinese culture is also one of the important carriers of American multiculturalism. According to statistics, China has established 110 Confucius Institutes in 
the United States so far. From 2016 to 2017, the number of Chinese students studying in the United States has exceeded 350,000 , accounting for $32.5 \%$ of the total number of international students in the United States. All of these are served as the guarantee that the United States has a huge potential to be a source of tourists.

India is ranked third in this list. As one of our largest neighbors, India has a huge tourist source market thanks to its large population. China has always been India's second largest trading partner. India is one of the fastest growing countries in the world. Its rapid economic growth offers huge potential for the development of its tourist market. In addition, as two ancient civilizations in the world, SinoIndian culture has a long history. Chinese Buddhism is introduced from ancient India. The number of Indian students studying in China is increasing year by year and Chinese culture has an increasing influence in India. Thus, India has great potential to be a source of tourists in the future.

\subsubsection{Countries with High Potential of Inbound Tourism}

Table 4 shows that the final scores of Singapore, Germany, Russia, the United Kingdom, Australia, Canada, and France are all positive. Therefore, these seven countries have certain potential to be the sources of tourists to various degrees.

Singapore is located in Southeast Asia and is adjacent to China. It is a multicultural nation of immigrants. The Chinese account for $74.2 \%$ of its total population. Moreover, Chinese is one of Singapore's official languages. In the formation of its culture, Chinese culture has exerted a significant influence on Singapore. Consequently, most Singaporeans have a great identity towards Chinese culture. With respects to its unique location, Singapore is one of the richest and most open countries, and it has become No. 1 in terms of investment in China in recent years. Concerning the above-mentioned, it has a great potential to be a source of tourists $[14,16]$.

Russia is bordered by the north of China and has always maintained a friendly and cooperative attitude towards China in diplomacy. As the same time, Chinese culture is attractive to Russia to a great extent. Every year, the number of Russian students is increasingly growing in China. As one of the "BRIC countries", like China and India, Russia has a relatively fast economic growth rate. Since 2010, China has always been Russia's largest trading partner. In this sense, it's believed that Russia has the potential to be a source of tourists.

Germany, the United Kingdom, and France as old developed countries, they all have highly developed economic systems, advanced science and technology, and a sound social security system. The residents in these countries have a strong ability and desire to travel. With the development of China's economy, China has strengthened its trade with Europe. Moreover, Chinese culture has exerted an increasing influence in there. According to statistics, there are 173 Confucius Institutes in Europe, ranked first among all continents. Thus, the UK, Germany and France still have certain potential to be sources of tourists.

Australia and Canada, as two new countries of immigrant, adopt a compatible and inclusive attitude towards cultures around the world. As a result, Chinese culture has a certain market in these two countries. As developed countries, both of them boast the rapid economic growth and wellestablished social welfare system. Their peoples have the economic ability to have an overseas trip. It's worthwhile to tap their potentials to be sources of tourists.

\subsubsection{Other Countries}

The evaluation results show that the remaining 9 countries get negative scores. Compared with the above countries, they have no strong potential to be the sources of tourists. Japan is highly representative. As China's largest maritime neighbor, Japan has been deeply influenced by Chinese culture since ancient times in language, writing, architecture, clothing, food and thought. However, the Japanese right-wing forces have risen in recent years. The territorial dispute over the Diaoyu Islands and the Prime Minister paying a blatant homage to the Yasukuni Shrine has made Sino-Japanese diplomatic relations tense. The appeal of Chinese culture in Japan has also been greatly reduced. In terms of economic and trade exchanges, China is an important trading partner and competitor of Japan. In summary, historical and political issues, territorial disputes, and economic frictions have complicated Sino-Japanese diplomacy and played a negative role for Japan to be a source of tourists

Malaysia, Indonesia, the Philippines, Mongolia and Thailand are all developing countries with low national income. They don't have strong ability and desire to travel. Their trade with China is far worse than that of developed countries such as the United States and the United Kingdom; and none of the above five countries belong to the East Asian cultural circle. The influence of traditional Chinese culture on these countries is far less than that of on Japan and South Korea. Consequently, they lack certain potential to be the sources of tourists. As to Italy, the Netherlands and New Zealand, they are located in Western Europe and Oceania respectively. With a small population base, they are far from China and have high transportation costs. Consequently, their potential of being a source of tourists are greatly limited [11, $13]$.

\subsection{The Influencing Factors of Evaluating the Potential of Inbound Tourism for Major Sources of Tourists}

\subsubsection{Direct Oblimin Results}

In Table 4, the rankings and comprehensive scores of main components in different countries are various from each other. Finding out the factors that influence the score of principal components plays a big role in directing the development of inbound tourism in China. In order to make the main influencing factors more clear, this paper rotates the compound matrix of principal components with the direct oblimin. Setting the value of $\delta$ as zero, as shown in Table 5 , a new compound matrix can be obtained after seventeen rotations. The factors with higher matrix on each principal component are the per capita national income, the rate of outbound tourism, the proportion of the 25-64 age group, the 
number of Confucius Institutes, the number of oversea students in China, and investment in China. Multiplying the absolute value of the above factors' matrix by the corresponding principal component contribution rate, the comprehensive matrix of each factor can be obtained. The results show that the six factors in order of importance are the rate of outbound tourism, the per capita national income, and the proportion of the 25-64 age group, the number of Confucius Institutes, the number of oversea students in China, as well as investment in China.

Table 5. Factors compound matrix after rotation and its comprehensive matrix of main factors.

\begin{tabular}{|c|c|c|c|c|c|c|c|}
\hline & F1 & F2 & F3 & F4 & Corresponding contribution rate & comprehensive load & Ranking \\
\hline $\mathrm{X} 1$ & 0.870 & -0.206 & -0.007 & -0.218 & 0.3430 & 0.2984 & 2 \\
\hline $\mathrm{X} 2$ & -0.239 & -0.571 & 0.256 & 0.410 & & & \\
\hline $\mathrm{X} 3$ & 0.879 & 0.164 & -0.037 & -0.210 & 0.3430 & 0.3015 & 1 \\
\hline $\mathrm{X} 4$ & 0.657 & 0.428 & -0.437 & -0.055 & & & \\
\hline X5 & 0.597 & 0.062 & 0.302 & 0.120 & & & \\
\hline X6 & 0.038 & 0.894 & 0.244 & -0.117 & 0.2673 & 0.2390 & 3 \\
\hline $\mathrm{X} 7$ & 0.364 & -0.224 & -0.117 & 0.609 & & & \\
\hline X9 & -0.264 & 0.335 & 0.771 & -0.241 & 0.1756 & 0.1354 & 5 \\
\hline $\mathrm{X} 10$ & 0.226 & -0.043 & -0.028 & -0.906 & 0.0543 & 0.0492 & 6 \\
\hline X11 & 0.357 & -0.499 & 0.453 & -0.348 & & & \\
\hline $\mathrm{X} 12$ & 0.695 & -0.452 & 0.033 & 0.241 & & & \\
\hline
\end{tabular}

\subsubsection{Analysis of Influencing Factors for Major Sources of Tourists}

According to Tables 4 and 5, South Korea is ranked first, mainly because it has the largest number of students studying in China and has a strong centripetal force towards Chinese culture. The number of Confucius Institutes in South Korea is 23, ranked second only to the United States and the United Kingdom, which means the Chinese culture has great influence on the country. The proportion of the 25-64 age group is as high as $72.9 \%$. The per capita national income is also far ahead and the willingness of the South Korean to travel abroad is strong. It has a close relation with China in economy and its investment in China is as high as 25.1 billion RMB. The number of Confucius Institutes in the United States is as high as 110 , accounting for $20 \%$ of the total number of Confucius Institutes around the world. The number of its students in China is on a yearly increase and is second only to South Korea, ranked second among the 19 major countries. In this sense, Chinese culture has a strong influence and appeal to the United States. The per capita national income of the United States is ranked second among nineteen countries. It has a sound social welfare system and has a strong economic capability. The people of the country have a strong willingness to travel. Moreover, the country tops in terms of investment in China. As to India, it has a certain rate of outbound tourism and has a larger population base than other countries. Therefore, India has a decent number of people who are willing to have a foreign trip. In terms of the number of foreign students, India is ranked fourth among 19 countries, second only to South Korea, the United States and Thailand, which indicates that it has a high degree of recognition towards Chinese culture. Moreover, India plays a leading role in terms of investment in China and the proportion of the 25-64 age group.

By comparison, Japan is ranked $15^{\text {th }}$ in terms of outbound tourism. Although Japan's per capita national income is relatively high, its work pressure is far greater than other developed countries due to its special national conditions.
The willingness of the Japanese to travel abroad is not strong enough. The proportion of the 25-64 age group accounts only for $61.2 \%$, ranking the bottom of the list. It is a country with a large aging population, which undoubtedly greatly increased the work pressure of young people. As a result, it reduced their willingness to travel abroad. Recently, the number of Japanese students has reduced year by year. Therefore, Japan got a low score over its potential to be a source of tourist. As for the Philippines, Indonesia, and Mongolia, the per capita national income of the three countries is relatively low and their rankings are behind, which implies to a certain extent that they lack the economic foundation needed for outbound tourism. In addition, their number of Confucius Institutes, the number of overseas students in China, and the investment in China rank at the end of the sequence of 19 major countries.

\section{Conclusion}

According to the study on the potential of major sources of tourists and its influencing factors, this paper concludes that the countries of tourists with the highest potential of inbound tourism are South Korea, the United States, and India respectively. The countries with high potential of inbound potential are Singapore, Germany, Russia, the United Kingdom, Australia, Canada and France. In addition, Indonesia, Mongolia, and the Philippines are at the end of the ranking. The main factors in order of importance are the rate of outbound tourism, the per capita national income, the proportion of the 25-64 age group, the number of Confucius Institutes and oversea students in China, as well as investment in China.

Among them, indicators such as the rate of outbound tourism, the per capita national income, the proportion of the 25-64 age group, reflect the economic development of the countries of tourists, on the other hand, they are the main factors influencing the travel of these countries to China. The rate of outbound tourism is the ability of outbound tourism 
and the willingness to travel abroad. The per capita national income can reflect the national affluence of the country of tourists in that outbound tourism is a relatively extravagant consumption that requires a certain economic foundation as a support. In general, both of them complement each other to some extent and are the most important factors influencing the inbound tourism in China. In the age distribution of all foreign tourists in China, the 25-64 age group accounts for the largest proportion. People under 25 years old are mainly children and students and over 64 years old are seniors. They all lack certain willingness to travel abroad. Generally speaking, the higher the proportion of the 25-64 age group in a country, the more people are willing to travel abroad. In this sense, the proportion of the 25-64 age group is also an important factor influencing the inbound tourism in China.

This paper pays attention to the number of Confucius Institutes and the number of overseas students in China. The ranking results tell that cultural appeal has exceeded the factors such as economic and trade exchanges with China and transportation costs in China. Having the economic ability and willingness to have a foreign trip, it's normal for people to take the destination into major consideration because countries and regions in the world boast their own unique human history and natural scenery. Foreigners choose to travel to China because of the unique charm of Chinese culture. In general, the more the number of Confucius Institutes in a country, the greater the influence and appeal of Chinese culture on it. The more students of a country studying in China, the greater the identity it has towards Chinese culture and the willingness to travel to China. Thus, the number of Confucius Institutes and the number of overseas students in China constitute important factors influencing a country to be source of tourists.

\section{References}

[1] Tien Pham, Leo Jago, Ray Spurr and Justin Marshall (2015). The Dutch Disease effects on tourism: The case of Australia. Tourism Management 46, 610-622.

[2] Ender Demir and Giray Gozgor (2017). What about relative corruption? The impact of the relative corruption on the inbound tourism to Turkey. International Journal of Tourism Research 19, 358-366.

[3] Jewoo Kim and Choong-Ki Lee (2017). Role of tourism price in attracting international tourists: The case of Japanese inbound tourism from South Korea. Journal of Destination Marketing \& Management 6, 76-83.

[4] Hassan F. Gholipour, Reza Tajaddini and Jeremy Nguyen (2016). Happiness and inbound tourism. Annals of Tourism Research 57, 251-253.

[5] Joan Catherine Henderson (2017). Destination Development: Trends in Japan's Inbound Tourism. International Journal of Tourism Research 19, 89-98.

[6] Pan Wenrong, LiuYuzhi, Deng Lulu (2017). The spatial evolution pattern of inbound tourism in China and its impact factors. Journal of Discrete Mathematical Sciences and Cryptography 20, 1291-1295.

[7] Funck (2012). The innovative potential of inbound tourism in Japan for destination development - a case study of Hida Takayama. Contemporary Japan 24, 121-127.

[8] Lin Haiying, Meng Nana, Li Wenlong. The Spatial and Temporal Evolution of the Market of Inbound Tourists from Inner Mongolia under the "One Belt, One Road" Strategy [J]. Regional Research and Development, 2016 (35).

[9] Lü Zhiqiang, Pang Rong, Dai Fuqiang. Analysis of the Time and Space Evolution of China's Tourism Industry and Tourism Environment Coordination in the Past Ten Years [J]. Tourism Resources, 2015 (31).

[10] Yang Weiqiong, Zhang Hua. Spatial Econometric Analysis of Foreigners' Travel to China [J]. Tourism Journal, 2015 (30).

[11] Yaping Liu, Yinchang Li, Parnpree Parkpian (2018). Inbound tourism in Thailand: Market form and scale differentiation in ASEAN source countries. Tourism Management 64, 22-36.

[12] Xu Xu and Markum Reed (2017). Perceived pollution and inbound tourism in China. Tourism Management Perspectives 21, 109-112.

[13] Elena Cavagnaro, Simona Staffieri, Fiona Ngesa (2015). Looking from a local lens: Inbound tour operators and sustainable tourism in Kenya. Research in Hospitality Management 5, 135-145.

[14] Wenming Shi, Kevin X. Li (2017). Impact of unexpected events on inbound tourism demand modeling: evidence of Middle East Respiratory Syndrome outbreak in South Korea. Asia Pacific Journal of Tourism Research 22, 344-356.

[15] Shi, Ji, Wang, Li (2016). Impacts of star-rated hotel expansion on inbound tourism development: evidence from China. Applied Economics 48, 3033-3048.

[16] Chor Foon Tang, Eu Chye Tan (2016). The determinants of inbound tourism demand in Malaysia: another visit with nonstationary panel data approach. Anatolia 27, 189-200. 